\title{
Functions of chemokines in the perineural invasion of tumors (Review)
}

\author{
MEI ZHANG ${ }^{1,2^{*}}$, ZHUO-LI ZHU ${ }^{1 *}$, XIAO-LEI GAO ${ }^{1,3}$, JIA-SHUN WU $^{1,2}$, \\ XIN-HUA LIANG ${ }^{1,3}$ and YA-LING TANG ${ }^{1,2}$ \\ ${ }^{1}$ State Key Laboratory of Oral Diseases; Departments of ${ }^{2}$ Oral Pathology and ${ }^{3}$ Oral and Maxillofacial Surgery, \\ West China Hospital of Stomatology, Sichuan University, Chengdu, Sichuan 610041, P.R. China
}

Received October 27, 2017; Accepted January 25, 2018

DOI: $10.3892 /$ ijo.2018.4311

\begin{abstract}
The perineural invasion (PNI) of malignant tumors is a form of tumor progression in which cancer cells encroach along nerves. PNI hinders curative resection. Residual tumor cells in or around nerves can bring about local recurrence, infiltration and metastasis. This behavior is usually associated with a poor clinical prognosis. Therefore, it is necessary to investigate novel ligand-receptor crosstalk between nerves and tumor cells that promote the process of PNI. Chemokines are regarded as one of pivotal factors involved in the process of PNI. The present review collates information provided by previous studies with regard to the role of chemokines in PNI. The study presents a definition of PNI in cancer, generalizes the biological characteristics and the expression of chemokines and their receptors in cancer types associated with PNI, and discusses the underlying molecular mechanisms of chemokines, the reciprocal interactions between chemokines and other factors in PNI, and the interconnectivity of the microenvironment and chemokines. The aim of the review is to thoroughly illustrate the molecular cues of chemokines in cancer with PNI and to identify novel antitumor targets.
\end{abstract}

\section{Contents}

1. Introduction

2. Biology of chemokines and their receptors

Correspondence to: Ms. Ya-Ling Tang, Department of Oral Pathology, West China Hospital of Stomatology, Sichuan University, 14, Section 3, Renminnan Road, Chengdu, Sichuan 610041, P.R. China E-mail: tangyaling@scu.edu.cn

Mr. Xin-Hua Liang, Department of Oral and Maxillofacial Surgery, West China Hospital of Stomatology, Sichuan University, 14, Section 3, Renminnan Road, Chengdu, Sichuan 610041, P.R. China E-mail: 1xh88866@scu.edu.cn; drliangxinhua@aliyun.com

*Contributed equally

Key words: perineural invasion, chemokines, G protein-coupled receptors, metastasis, microenvironment, targeted therapy
3. Chemokines promote the progression of cancer

4. Role of chemokines in cancer with PNI

5. Reciprocal interaction between other factors and chemokines in PNI

6. Interconnections between the microenvironment and chemokines in PNI

7. Conclusions

\section{Introduction}

Perineural invasion (PNI) is the existence of cancer cells along the sides of nerves and/or inside the epineural, perineural and endoneural spaces of the neuronal sheath $(1,2)$. Solid tumors disseminate in four well-known ways: Direct invasion of surrounding tissues, lymphatic spread, hematogenous spread and seeding along body cavities, with PNI regarded as the fifth route of cancer spread (1). PNI is considered as a marker of poor prognosis for numerous malignant neoplasms, including head and neck (1,3), pancreatic (4), prostate (5), colorectal (6), gastric (7), salivary (8) and breast (9) cancer. It is closely associated with increased post-operative locoregional recurrence and a decreased survival rate.

PNI was first proposed more than 100 years ago, and a clear shift in the understanding of its pathogenesis has occurred. The traditional theory for the pathogenesis of PNI was that tumor cells spread passively along the connective tissues that covered the nerves or through the perforating vessels of the nerve beams, where there was least resistance (10). However, recently, studies have revealed that cancer cells have an innate ability to actively migrate along nerves in a mechanism called neural tracking, which is supported by various molecules, including nerve growth factor (NGF), glial cell line-derived neurotrophic factor (GDNF), neural cell adhesion molecule, matrix metalloproteinases (MMPs) and chemokines, which are secreted by tumor cells and other non-tumor cells in the tumor microenvironment (11). Among these molecules, the role of chemokines and their receptors in the PNI of malignant neoplasms have gained a high degree of attention recently (Fig. 1). The present review will evaluate the biology and the expression of chemokines and their receptors in cancer type associated with PNI, thoroughly discuss the underlying 


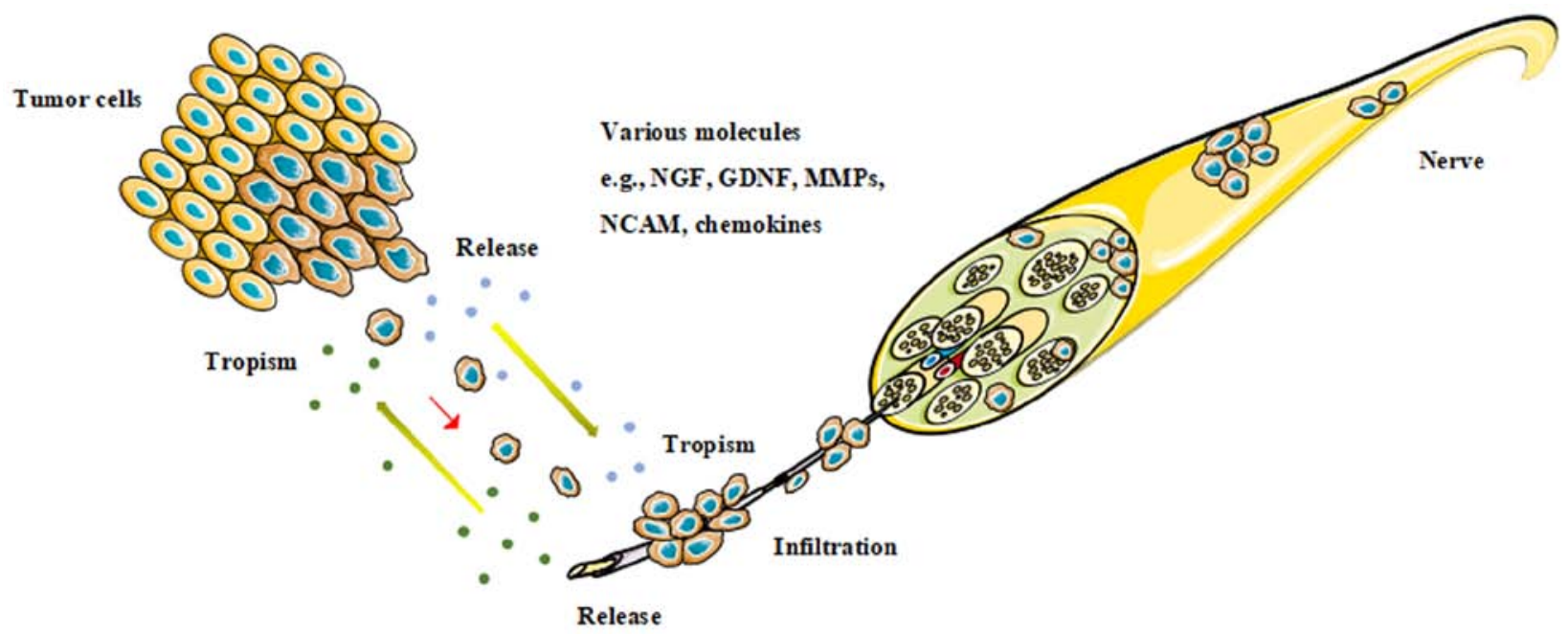

Figure 1. Schematic representation of molecules involved in perineural invasion. Various molecules, including NGF, GDNF, NCAM and chemokines, secreted by tumor cells and nerve cells in the tumor microenvironment, promote tumor cell migration toward nerves and invasion of the nerves. NGF, nerve growth factor; GDNF, glial cell line-derived neurotrophic factor; NCAM, neural cell adhesion molecule; MMP, matrix metalloproteinase.

molecular mechanisms of chemokines in PNI and identify novel antitumor targets.

\section{Biology of chemokines and their receptors}

Chemokines are a group of small soluble peptides $(8-14 \mathrm{kDa})$ secreted by various cell types, including epithelial, endothelial and immune cells, as well as certain tumor cells (12-14). Approximately 50 chemokines have been detected, and they are divided into four chemokine ligand subtypes, known as the $\mathrm{C}$, $\mathrm{CC}, \mathrm{CXC}$, and $\mathrm{CX} 3 \mathrm{C}$ subtypes, respectively, according to the number and relative spatial position of their conserved cysteine residues in the amino-terminal region of the peptides (Fig. 2). The majority of chemokines are composed of the $\mathrm{CC}$ and CXC subfamilies, including 28 (CCL1-28) and 16 (CXCL1-16) members, respectively. The $\mathrm{C}$ and $\mathrm{CX} 3 \mathrm{C}$ group are two minor subfamilies, and only 2 members (CL1 and CL2) and 1 member (CX3CL1), respectively, have been described (14-17). Chemokines are pivotal components and orchestrators during the process of immune and inflammatory reactions, acting by controlling the adhesion and cross-endothelial movement of leukocytes, lymphocytes and monocytes from the circulatory system to corresponding inflammatory sites. Chemokines are also involved in other processes, including embryonic growth and development, homeostasis of the central nervous system, wound healing, and the occurrence and development of tumors $(18,19)$.

Chemokines unleash their broad biological functions by combining with their $\mathrm{G}$ protein-coupled receptors (GPCRs). These are transmembrane proteins with an extracellular $\mathrm{N}$-terminal domain, which is necessary for specific binding and activation of their corresponding ligands, and an intracellular C-terminus, which is essential for receptor-mediated signal transduction $(15,20)$ (Fig. 3). Chemokine receptors can be divided into $\mathrm{C}$ receptor (CR1), CC receptor (CCR1-10), CXC receptor (CXCR1-7) and CX3C receptor (CX3CR) according to the subfamilies of chemokine ligands they bind to. In the immune and inflammatory reactions, several chemokine ligands can interact with a single receptor, and a single chemokine ligand may also activate multiple receptors.
Conversely, a homeostatic chemokine ligand has a relatively strict specificity and a single receptor can be activated by only one or two chemokines typically $(21,22)$.

In general, heterotrimeric GPCR is composed of an $\alpha$ subunit and a $\beta \gamma$ heterodimer. The $\beta \gamma$ subunit acts as a $\mathrm{G} \alpha$ inhibitor by binding to the $\mathrm{G} \alpha$ subunit. Once a chemokine binds to and activates its receptor, conformational changes in the transmembrane region of GPCR will be induced, leading to the transition of the Ga subunit from inactive guanosine diphosphate-bound to active guanosine triphosphate (GTP)bound and dissociation from the $\beta \gamma$ heterodimer (23-25). Thus, the downstream signaling effectors, including $G$ proteincoupled receptor kinases, ion channels, protein kinase $\mathrm{C}$ and phospholipase $\mathrm{C}$ can be initiated. This further brings about signaling cascades, including the activation of Ras homolog gene family A kinase, extracellular signal-regulated kinase (ERK), mitogen-activated protein kinase (MAPK), phosphoinositide 3-kinase (PI3K), protein kinase $\mathrm{B}(\mathrm{Akt})$ and Janus-activated kinase-2, which can promote gene transcription and evoke various cellular responses, including cell proliferation, reorganization of the actin cytoskeleton, shape change and migration (25-28) (Fig. 3).

\section{Chemokines promote the progression of cancer}

Studies have demonstrated that chemokines serve an important role in the progression of tumors (29). Chemokines, as autocrine growth factors, can accelerate tumor growth via activation of growth factor receptors. Chemokines also promote the proliferation of tumor cells by making the tumors insensitive to anti-growth signals $(30,31)$.

Chemokines can modulate tumor invasion and metastasis by promoting epithelial mesenchymal transition (EMT), upregulating the expression of proteases and downregulating the expression of E-cadherin and integrin through a series of signaling pathways, including the MAPK/ERK/PI3K/ Akt signaling pathways. Furthermore, chemokine receptors expressed by tumor cells can make a response to their corresponding chemokine ligands and migrate directionally 


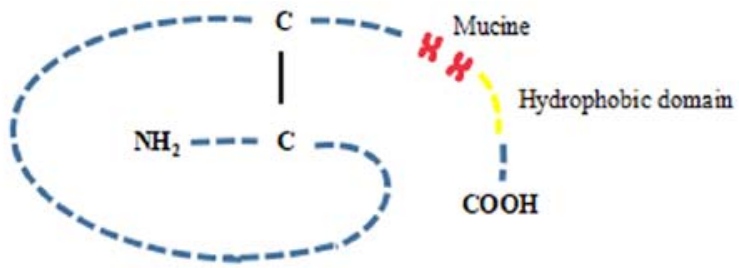

Chemokine C

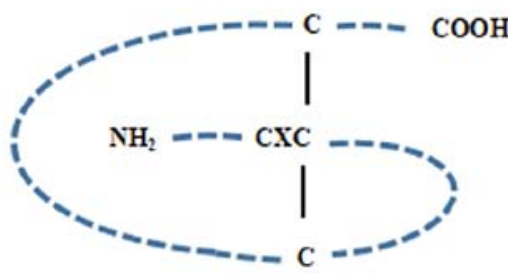

Chemokine CXC

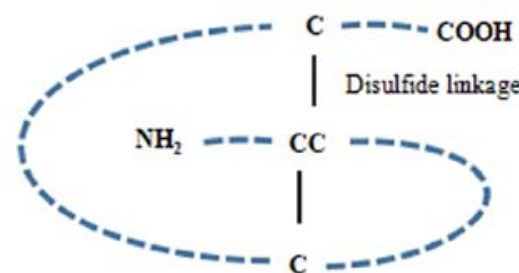

Chemokine CC

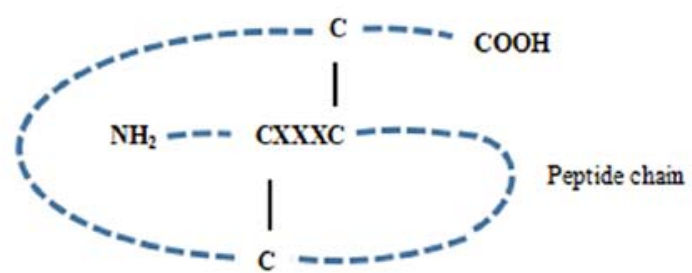

Chemokine CX3C

Figure 2. Structure of the four subtypes of chemokine ligand.

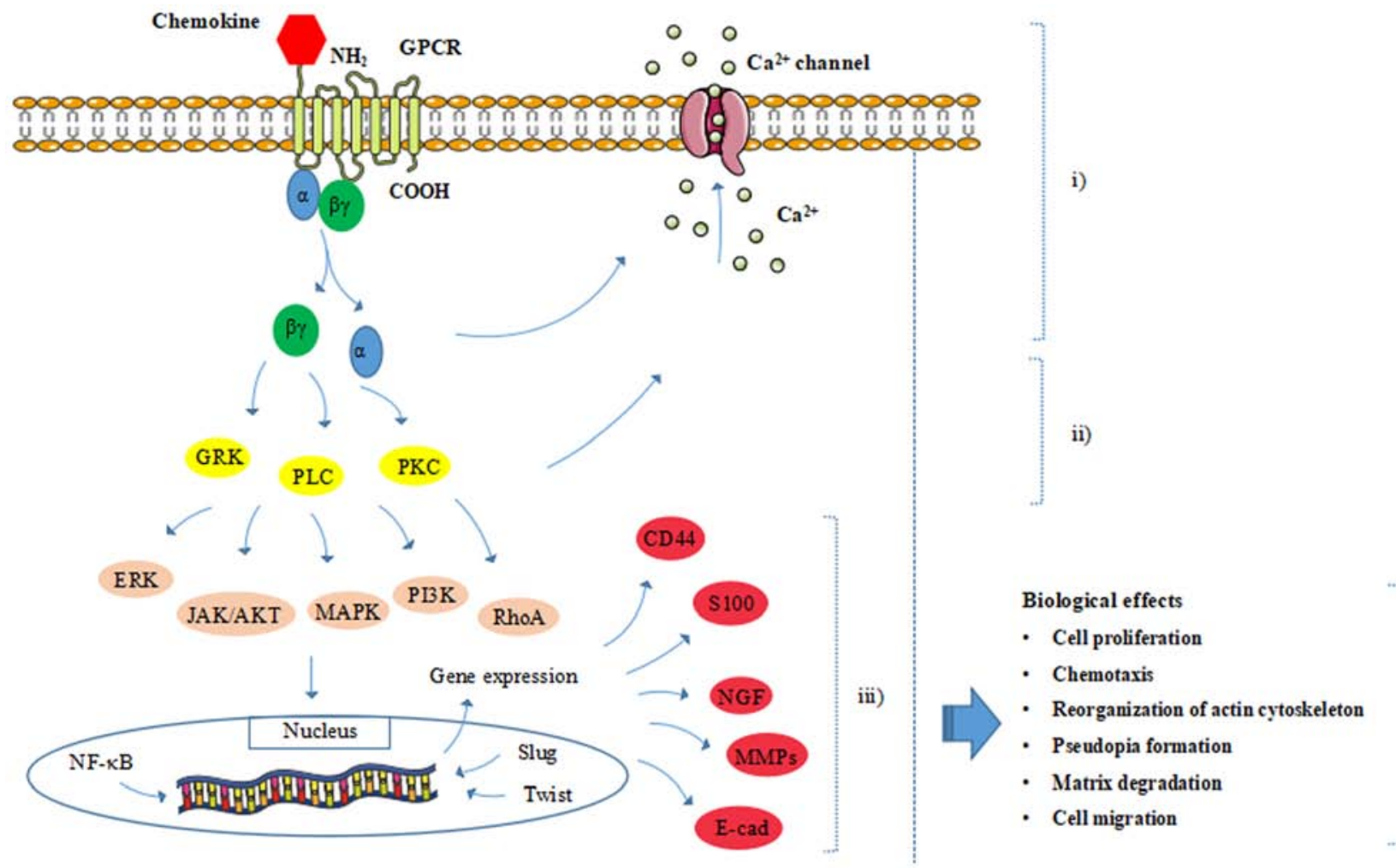

Figure 3. Chemokine-induced signal transduction in cancer with perineural invasion. i) The binding of chemokine ligands to their GPCRs leads to the activation of an $\alpha$ subunit and a $\beta \gamma$ heterodimer, and dissociation from GPCR. ii) The downstream signaling effectors, including GRK, ion channels, PKC and PLC, can be initiated. iii) This further leads to signaling cascades, such as the activation of RhoA kinase, ERK, MAPK, PI3K, Akt and JAK-2, which can promote transcription and expression of genes such as CD44, NGF and MMPs. iv) All above evoke broad biological effects, including cell proliferation, chemotaxis, reorganization of actin cytoskeleton, pseudopodia formation, matrix degradation and cell migration. GPCR, G protein-coupled receptors; GRK, GPCR kinases; PKC, protein kinase C; PLC, phospholipase C; RhoA, Ras homolog gene family A; ERK, extracellular signal-regulated kinase; MAPK, mitogenactivated proteins kinase; PI3K, phosphoinositide 3-kinase; Akt, protein kinase B; JAK-2, Janus-activated kinase-2; CD44, cluster of differentiation 44; NGF,

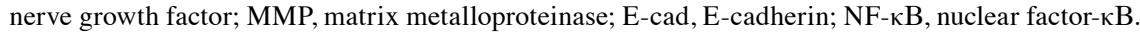

towards concentration gradients of chemokine ligands to achieve organ-specific metastases $(32,33)$. Another potential mechanism is that the binding of chemokine ligands to their receptors may induce membrane wrinkling and the formation 
Table I. Expression of chemokines and their corresponding receptors in cancer with PNI.

\begin{tabular}{llll}
$\begin{array}{l}\text { Chemokine } \\
\text { ligand }\end{array}$ & $\begin{array}{c}\text { Chemokine } \\
\text { receptor }\end{array}$ & \multicolumn{1}{c}{$\begin{array}{c}\text { Tumors with } \\
\text { PNI }\end{array}$} & (Ref.) \\
\hline CXCL12 & CXCR4 & $\begin{array}{l}\text { Prostate cancer } \\
\text { Pancreatic cancer }\end{array}$ & $\begin{array}{l}(34) \\
\text { Breast cancer }\end{array}$ \\
& & HNSCC & $(44,45)$ \\
& & Pancreatic cancer & $(50)$ \\
CX3CL1 & CX3CR1 & Breast cancer & $(64,60)$ \\
& & Prostate cancer & $(62)$ \\
& & HNSCC & $(63)$ \\
CCL2 & CCR2 & Prostate cancer & $(11,35)$ \\
& & Breast cancer & $(64)$ \\
& & Hepatic carcinoma & $(65)$ \\
CCL5 & CCR5 & Prostate cancer & $(66)$ \\
& & Lung adenocarcinoma & $(67)$ \\
& & SACC & $(36)$ \\
CXCL13 & CXCR5 & Prostate cancer & $(68)$ \\
& & Colorectal & $(69)$
\end{tabular}

PNI, perineural invasion; HNSCC, head and neck squamous cell carcinoma; SACC, salivary adenoid cystic carcinoma.

of pseudopodia in tumor cells, which facilitates tumor cells to adhere to and pass through the extracellular matrix (ECM) and basal membrane to achieve invasion and metastasis (34).

\section{Role of chemokines in cancer with PNI}

Recently, chemokines have been widely investigated in the process of PNI, particularly the CXCR4/CXCL12, CCL2/ CCR2, CCL5/CCR5, CXCL13/CXCR5 and CX3CL1/ CX3CR1 signaling axes (11,35-37). The significance and associated mechanisms of these chemokine signaling axes in cancer with PNI will now be discussed (Table I) (Fig. 3).

CXCL12/CXCR4 in cancer with PNI. The CXCL12/CXCR4 axis is one of the most widely studied signaling pathways among the chemokine family and their receptors. CXCR4 functions through combining with its specific chemokine ligand, CXCL12, also known as chemokine stromal cell-derived factor $1 \alpha$ (38). This signaling pathway has been found to serve multiple functions, including regulating the proliferation of cells, angiogenesis and EMT (39). This pathway is also regarded as an important candidate in support of the occurrence, invasion and metastasis of tumors (40-42). Furthermore, CXCR4-positive tumor cells can migrate toward distant organs as a response to CXCL12 concentration gradients (38).

A previous study showed that CXCL12 expression in prostate cancer was significantly stronger than that in prostate hyperplasia. CXCR4 was mainly expressed in tumor cells, and CXCL12 was expressed highly in Schwann cells around the tumor. In vitro, the invasiveness of tumor cells treated with CXCL12 increased significantly, and this invasiveness could be inhibited by the CXCR4-specific inhibitor AMD3100 (34). Therefore, AMD3100 may be a potential anti-neoplastic agent. In addition, in another PNI-associated tumor, pancreatic cancer, CXCR4 was examined in 6 pancreatic cancer lines, CFPAC-1, Panc-1, AsPC-1, SW1990, MiaPaCa-2 and BxPc-3 cells. Weak expression of CXCL12 in pancreatic tumor cells was detected by ELISA, although it was not detected by reverse transcription-quantitative polymerase chain reaction (RT-qPCR) or western blot assays. RSC96 Schwann cells and newborn rat dorsal root ganglia (DRG) showed that the expression of CXCL12 was strong, as determined by immunofluorescence analysis and ELISA (43). In vitro and in vivo analyses have revealed that the CXCL12/CXCR4 signaling axis can promote the chemotactic migration of pancreatic cancer cells towards nerve cells, which can be inhibited by blocking the CXCL12/CXCR4 pathway axis using CXCR4 short hairpin RNA and AMD3100.

In addition, Kang et al (44) confirmed that CXCL12 was observed in the human breast cancer MDA-MB-435S cell line, but that it was not expressed in the MDA-MB-231 cell line, as determined by RT-PCR. CXCR4 was detected in the MDA-MB-231 and MDA-MB-435S cell lines (45). When silencing CXCL12 in MDA-MB-435s via a ribozyme transgene, the invasion and migration potential of the tumor cells significantly declined. However, transfection of CXCL12 increased the invasion and migration abilities of the MDA-MB-231 cells (45). The CXCL12/CXCR4 axis can promote PNI by increasing Rho GTPase activities, mediating the polymerization of F-actin and stimulating transmembrane mobilization of $\mathrm{Ca}^{2+}(38,46)$. The activation of the CXCL12/ CXCR4 axis also can induce phosphorylation of the focal adhesion components (e.g., related adhesion focal tyrosine kinase, Paxillin and Crk) and pseudopodia formation, facilitating tumor cell adhesion to the basement membrane components, and promoting invasion and metastasis $(45,47)$. Furthermore, CXCR4 also exhibits high expression in gliomas $(48,49)$ and other cancers of non-neural origin with PNI, including head and neck squamous cell carcinoma (HNSCC) (50). The combination of CXCL12 and its receptor CXCR4 may promote cell proliferation, chemotaxis and invasion by activating multiple signaling pathways, including ERK/MAPK and $\mathrm{PI} 3 \mathrm{~K} / \mathrm{AKT}$, and leucine-rich repeat-containing protein 4 can block the chemotaxis of tumor cells and PNI induced by the CXCL12/CXCR4 axis via curbing the ERK/MAPK and PI3K/ AKT signaling pathways $(49,51)$. CXCR4 may downregulate the expression of p53, p21 and E-cadherin, and upregulate the expression of cluster of differentiation (CD)44, resulting in the increased adhesion of tumor cells and the PNI ability (52).

The aforementioned studies suggest that tumor cells express a high level of CXCR4, that the metastasis-targeted organs and nerves exhibit high expression of CXCL12, and that CXCR4-positive tumor cells are attracted towards target organs expressing CXCL12, thus promoting the PNI of the tumor. However, given the fact that CXCL12 was also detected in prostate and pancreatic cancer cells, an autocrine or paracrine pathway may also participate in the process of PNI, mediated by chemokines and their receptors $(34,43)$.

CX3CL1/CX3CR1 in cancer with PNI. CX3C motif chemokine ligand 1 (CX3CL1), also known as fractalkine or neurotactin, 
is the only member of the CX3C subfamily of chemokines and forms a high affinity signaling axis by binding to its chemokine receptor CX3CR1 exclusively (53). CX3CL1 can be abundantly expressed by activated endothelial cells and neurons, and it can exist in either a membrane-anchored adhesion molecule or a soluble chemoattractant form $(54,55)$. Previous studies have shown that the CX3CL1/CX3CR1 axis serves an important role in the nervous system by facilitating the information exchange among neurons, glia and microglia, promoting nerve generation and restricting tissue damage during the inflammatory response. This occurs by promoting the mobilization of intracellular $\mathrm{Ca}^{2+}$, chemotaxis and the inhibition of apoptosis, induced by the Fas signaling pathway or mediated by the activation of LPS $(45,56)$. In addition, in nerve-derived tumors, including glioma and neuroblastoma, CX3CR1 is highly expressed and involved in the adhesion, transendothelial migration and invasion of tumor cells (57-59).

Notably, CX3CR1 has also been detected in certain tumors of non-neural origin, including pancreatic $(54,60)$, breast (61) and prostate (62) cancer, and HNSCC (63), which are widely known to invade and metastasize along peripheral nerves frequently. In a pancreatic cancer study, up to $90 \%$ of the surgical specimens were CX3CR1-positive, and $56 \%$ exhibited a high intensity score according to immunohistochemical staining (60). CX3CR1 mRNA expression was detected in pancreatic cancer cell lines by RT-PCR, and the intrapancreatic nerves were demonstrated to express CX3CL1, while the pancreatic cancer cells expressed CX3CL1 only weakly (60). In vitro, CX3CL1 expression could induce the migration of CX3CR1-positive pancreatic cancer cells in a dose-dependent manner, thus promoting cancer cell adhesion to nerve cells through activation of GPCRs and redistribution of $\beta 1$ integrins and focal adhesion kinase. In vivo, pancreatic cancer cells expressing CX3CR1 were found to infiltrate the peripheral nerves when CX3CR1-positive pancreatic cancer cells were injected into the mice at the middle of the back, while peripheral nerve invasion was not observed in tumors from CX3CR1-negative cells (60).

Andre et al (61) found that CX3CR1 was closely associated with the invasion and metastasis of prostate cancer cells to the bone, whose bone marrow endothelial cells and differentiated osteoblasts secreted CX3CL1. Furthermore, in breast cancer, CX3CR1 was determined to forecast metastasis to the brain, where CX3CL1 was expressed abundantly (62). These results suggested that the $\mathrm{CX} 3 \mathrm{CX} 1 / \mathrm{CX} 3 \mathrm{CR} 1$ axis may serve a pivotal role in the invasion and metastasis of prostate and breast cancer, although its specific involvement in PNI had not been investigated.

Other chemokine signaling axes associated with PNI. Previous studies demonstrated that 20 out of $21(95 \%)$ specimens with PNI exhibited positive expression of CCR 2 in the cytoplasm in 34 prostate cancer cases assessed by immunohistochemistry. Just 3 specimens exhibited positive expression of CCR2 in the 13 cases of prostate cancer without PNI. The in vitro co-culture model and the in vivo mouse model demonstrated that CCL2 released by DRG facilitated CCR2-expressing prostate cancer migration and PNI $(11,35)$. Western blotting showed that $\mathrm{p}-\mathrm{MEK} 1 / 2$ and $\mathrm{p}$-Akt expression was upregulated in prostate cancer cells. The expression of p-Akt could be inhibited totally and the expression of $\mathrm{p}-\mathrm{MEK} 1 / 2$ could be decreased by anti-CCL2 antibody. Thus, CCL2 may promote the invasion and PNI of prostate cancer by activating Akt and MAPK pathways through CCL2/CCR2 (35). CCR2 also exhibits high expression in breast and hepatic carcinoma, and it can promote the motility and invasion of cancer cells by binding to its ligand CCL2 through mothers against decapentaplegic homolog3 (Smad3) protein and p42/44 MAPK-dependent mechanisms $(64,65)$. Thus, Akt, MAPK and Smad3 may be novel targets of antitumor therapy.

CCR5, receptor of CCL5, is primarily expressed in prostate cancer and lung adenocarcinoma, and is closely associated with the invasion and metastasis of these tumors $(66,67)$. In another PNI tumor, salivary adenoid cystic carcinoma (SACC), CCR5 and CCL5 expression was detected by flow cytometric analysis and immunofluorescence analysis. Migration and invasion assays showed that the CCL5/CCR5 axis can promote the invasion of nerves in the SACC- 83 cell lines by $\mathrm{Ca}^{2+}$ elevation and the rearrangement of the actin cytoskeleton (36).

In addition, CXCL13 and CXCR5 expression presents with a significant positive correlation with the occurrence of PNI, particularly in prostate (68) and colorectal (69) cancer, where CXCR5 is overexpressed. CXCL13, the stroma-derived ligand of CXCR5, can stimulate the expression of CXCR5 in prostate and colorectal tumor cells, leading to the phosphorylation of ERK and AKT, and the upregulation of MMPs, thus promoting the PNI of tumor cells (68-71).

\section{Reciprocal interaction between other factors and chemokines in PNI}

MMPs. MMPs, a group of zinc-dependent endopeptidases that can degrade numerous types of components of the ECM, are believed to promote the invasion and metastasis of tumors (67). Previous studies showed that certain components secreted by peripheral nerves, including NGF and GDNF, or the activation of COX-2 and prostaglandin E2 induced by the combination of tumor necrosis factor- $\alpha(\mathrm{TNF}-\alpha)$ and its receptor, can promote tumor cells to secrete MMPs and then facilitate tumor cells to invade nerve tissues in a number of tumors, including cholangiocarcinoma (CCA) and pancreatic cancer (72-74). Additionally, MMP-2 and MMP-9 can be upregulated by extracellular MMP inducer (EMMPRIN, CD147), a transmembrane glycoprotein belonging to the immunoglobulin superfamily, thus achieving PNI in SACC (75). Blocking of EMMPRIN by its antibody or silencing of EMMPRIN expression by RNA interference could effectively inhibit the proliferation and PNI activity of SACC cells, and reduce the secretion of MMP-2 and MMP-9 in SACC-83 cells (76,77).

Importantly, recent studies have shown that MMPs can also respond to chemokines and their corresponding chemokine receptors to promote PNI in certain tumors. The expression and activity of MMP-2 and MMP-9 in human glioblastoma can be markedly upregulated by the CCL12/ CXCR4 axis, mediated through activation of the ERK1/2 and Akt signaling pathway (49). In the progression of breast and pancreatic cancer, the autocrine CCL12-CXCR4 signaling pathway can promote PNI by increasing the secretion of and promoting the activation of MMP-2 and MMP-9 $(43,45)$. The CXCL12/CXCR4 and CXCL13/CXCR5 signaling axes have 
been demonstrated to induce prostate cancer cells to secrete MMP-2 and MMP-9, which degrades the matrix around the tumor and the nerve tissue, promoting PNI $(34,68)$ (Fig. 3).

$N G F$. NGF was the first member of the neurotrophic factor family to be identified, and was widely expressed in tumor tissues, and involved in tumorigenesis and tumor growth (78). An increasing number of studies have shown that NGF and its receptor tropomyosin receptor kinase A (TrkA) are overexpressed, and that the combination of NGF and TrkA promotes cancer cell growth, increases invasiveness and metastasis, and eventually causes nerve invasion in a number of human cancer types, including CCA, and pancreatic and prostate cancer (79-81).

It has been suggested that chemokines can increase NGF expression, which further accelerates the process of PNI by receptor binding $(34,43)$. The mechanism of the combination of NGF and TrkA promoting invasive behaviors acts to increase the synthesis and release of MMPs via the activation of the p44/42 MAPK signaling pathway $(82,83)$. The combination of NGF and TrkA can facilitate nerve cellular axon growth in the direction of the tumors by supplying chemical tropisms $(79,84)$. The overexpression of NGF and TrkA also contributes to the PNI of SACC (85). Additionally, NGF may upregulate the expression of $\mathrm{S} 100$ and reduce the expression of E-cadherin, leading to decreased adhesion between cancer cells, an increased ability for metastasis and ultimately, nerve tissue invasion in SACC $(86,87)$ (Fig. 3).

Nuclear factor $\kappa B(N F-\kappa B)$. NF- $\kappa B$ belongs to the transcription factors family, and the heterodimeric complex of the p65 and p50 subunits is the predominant form of NF- $\mathrm{kB}$; it is physically confined to the cytoplasm of normal cells and remains inactive through interaction with the NF- $\mathrm{KB}$ inhibitory protein (88). Following stimulation by various reagents (e.g., cytokines, viruses, growth factors and DNA damaging agents), a series of signaling events promote the $\mathrm{p} 65 / \mathrm{p} 50$ heterodimer to dissociate from the NF- $\mathrm{KB}$ inhibitory protein and translocate to the nucleus. This causes the activation of the expression of various genes involved in the prevention of apoptosis (89), and the promotion of the invasion and metastasis of cancer cells $(90,91)$.

NF- $\mathrm{KB}$ is also closely associated with the PNI potential of tumors. Huang et al (91) reported that NF- $\mathrm{KB}$ may function through the induction of CXCR4, which is one of the $\mathrm{NF}-\mathrm{\kappa B}$ target genes, containing a putative NF- $\mathrm{KB}$ binding site (5'-GAGGCATTTCC-3', 230-240bp) in the promoter region (92). In glioma, Esencay et al (48) found that the activation of NF- $\mathrm{KB}$ could induce CXCR4 expression and promote the migration of tumor cells. CXCR4 silencing could suppress the invasion and adhesion potential of U87 cells and pancreatic cancer cells, and decrease the transcriptional activity of NF- $\kappa B$ promoter $(43,52)$. CCR7 could activate MMP2 and MMP9 through the NF- $\kappa B$ signaling pathway to mediate the migration and invasion of human malignant glioma, and these biological effects could be reversed by treatment with small interfering CCR7 or a CCR7 neutralizing antibody in vitro (93). In another PNI tumor, CCA, studies showed that $\mathrm{NF}-\kappa \mathrm{B}$ signaling could be activated by the CCL5/CCR5 axis through increasing the expression of MMP2 and MMP9, thus contributing to the invasion and metastasis of tumor cells, which could be inhibited by CCL5 neutralizing antibody or CCR5 inhibitor maraviroc (94). Wang et al (95) found that CX3CL1/CX3CR1 could promote the invasion of pancreatic cancer through the activation of the NF- $\mathrm{kB}$ signaling pathway (Fig. 3).

Slug. Slug (Snail2), a member of the Snail family of zincfinger transcription factors, is known to serve pivotal roles in the process of cell migration, ranging from the formation of a number of tissues during embryonic development to the acquisition of invasive and metastatic properties in epithelial tumors $(96,97)$. It was reported that the expression of Slug was associated with PNI in different tumors, including human breast cancer (98), pancreatic cancer (99) and SACC (100). Slug mediates the PNI of these tumors mainly by promoting EMT in epithelial cells $(100,101)$. He et al (102) found that Slug promoted PNI and the metastatic capacity of SACC via the ERK/MAPK signaling pathways, and MAPK-knockdown reduced the expression of Slug in SACC cells (103).

Studies demonstrated that CCL18 could trigger the invasiveness and metastasis of oral squamous cell carcinoma, and that Slug-knockdown could reverse CCL18-induced EMT (104). The CCL21/CCR7 pathway led to the occurrence of the EMT process by activating the Slug pathway, and it promoted migration and invasion in human chondrosarcoma and lung cancer $(105,106)$. CCL18 promotes the invasion and metastasis of gastric cancer cells by increasing the expression of Slug and promoting EMT (107). The CXCL12/CXCR4 signaling axis has also been shown to be closely correlated with progression and the metastatic characteristics of CCA through Slug-induced EMT (108). These results indicated that Slug-induced EMT is involved in chemokine signaling (Fig. 3); however, whether chemokine signaling axes may promote tumor PNI via Slug-induced EMT remains unclear.

Twist. Twist, a transcription factor, belongs to the family of basic helix-loop-helix proteins and can bind to E-box regions in the promoters of certain genes to activate or inhibit transcription $(109,110)$. Upregulation of Twist was found in certain human tumors, including breast cancer (111), prostate cancer (112) and gastric cancer (113). Twist mainly functions by promoting EMT in malignant tumors $(111,114)$.

Recently, attention has been focused on the association between chemokine signaling axes and Twist in malignant tumors. Chen et al (115) reported that the CCL2/CCR2 axis could enhance EMT by upregulating the expression of Twist in non-small cell lung cancer. Low-Marchelli et al (116) found that CCL2 recruited macrophages to promote tumor progression by activating Twist signaling. Studies of Yang et al and Xu et al showed that CXCL12/CXCR4 may upregulate Twist through ERK and PI3K/AKT signaling, leading to the progression of EMT and the invasion and metastasis of tumor cells in human glioblastoma $(111,117)$. Koo et al $(118)$ found that CXCL11 could promote the invasive capacity of epithelial ovarian cancer via the enhancement of Twist expression. In addition, the CCR7 pathway upregulated Twist expression via ERK and PI3K/AKT signaling to manage EMT in pancreatic ductal adenocarcinoma (119). All the aforementioned studies showed that chemokines may be involved in tumor PNI through 
Twist-induced EMT; however, the concrete mechanisms between Twist and PNI require further investigation (Fig. 3).

\section{Interconnections between the microenvironment and chemokines in PNI}

The expression and roles of chemokines and their receptors in malignant neoplasms can also be regulated by various microenvironmental factors, including chronic inflammation, hypoxia, hepatocyte growth factor (HGF) and vascular endothelial growth factor (VEGF) $(44,48)$. Biphasic effects exist between chronic inflammation and chemokines. Franciszkiewicz et al (120) reported that chronic inflammation, which was partly driven by the chemokine signaling axis, was closely associated with the development of gastrointestinal malignancies $(120,121)$. By contrast, chemokine expression can also be induced by inflammation. For example, CX3CL1 expression was significantly driven by inflammation in vitro, and pro-inflammatory TNF- $\alpha$ and interferon- $\gamma$ could induce a higher expression level of CX3CL1 mRNA (122).

Hypoxia can influence the occurrence and development of tumors through the induction of chemokines and their receptors $(123,124)$. For example, hypoxic conditions within solid tumors may induce CXCL12 and CXCR4 expression via hypoxia inducible factor-1 (HIF-1) and VEGF, contributing to the adhesion, migration and PNI of tumor cells (123). In glioblastoma and breast carcinoma, necrotic foci and the pseudopalisading regions are hypoxic and are the main distribution sites of HIF-1 and VEGF, where overexpression of CXCR4 exists $(44,125)$. Similarly, under hypoxia, the metastasis of breast cancer was promoted by increasing the expression of CCR5 and its ligand CCL5 at the metastasis site via HIF-1 (126). Furthermore, hypoxia induces increased CCR7 expression in lung cancer cells, which further promotes the invasion of tumor cells and lymph node metastasis (127). In prostate cancer and pancreatic ductal adenocarcinoma, cancer invasion and metastasis is closely associated with the CX3CR1 expression of tumor cells, which is induced by hypoxia, and the ligand CX3CL1 is mainly expressed at the site of metastasis $(128,129)$.

HGF, a multifunctional cytokine secreted by fibroblasts and other stromal cells in tumors, exerts multiple functions in tumors, including proliferation, invasion and metastasis (130-133). HGF can upregulate the expression of CXCR4 protein in a number of tumors, including breast carcinoma and glioma, and HGF pre-treatment increases cancer cell migration toward CXCL12 via NF- $\kappa \mathrm{B}(44,48)$.

Hence, HIF-1, HGF and VEGF are considered potential targets of anticancer therapies. In fact, some of these inhibitors are in clinical trials as anticancer therapy drugs. For example, farnesyltransferase inhibitors, HGF binding peptide-1 and bevacizumab are treated as tumor therapeutic agents targeting HIF-1, HGF and VEGF, respectively (48,134-136).

\section{Conclusions}

PNI occurs in a number of human malignant neoplasms and is closely associated with postoperative relapse and a reduced survival rate. Accumulating evidence has indicated that chemokines and their corresponding receptors serve pivotal roles in the process of PNI. Although they are discussed in detail in this review, the precise mechanisms of chemokines in PNI deserve further investigation. With the development of molecular biology and advancements in proteomics technology, an increasing number of pivotal molecular markers associated with chemokines will be found in cancer with PNI. This should be conducive to improving our understanding of the mechanism of PNI and highlight novel chemokine-targeted drugs in the clinic to decrease relapses caused by the PNI of tumors.

\section{Acknowledgements}

Not applicable.

\section{Funding}

This study was supported by the National Program on Key Research Project of China (grant no.2016YFC0902700), the National Natural Science Foundation of China (grant nos. $81772891,81372891,81672672$ and 81572650) and the State Key Laboratory of Oral Diseases Special Funded Projects (2016).

\section{Availability of data and materials}

Not applicable.

\section{Authors' contributions}

MZ and ZZ wrote and edited the manuscript. XG and JW provided scientific revision of the manuscript. YT and XL prepared and reviewed the manuscript.

\section{Ethics approval and consent to participate}

Not applicable.

\section{Consent for publication}

Not applicable.

\section{Competing interests}

The authors declare that they have no competing interests.

\section{References}

1. Liebig C, Ayala G, Wilks JA, Berger DH and Albo D: Perineural invasion in cancer: A review of the literature. Cancer 115: 33793391, 2009.

2. Lesnik DJ and Boey HP: Perineural invasion of the facial nerve by a cutaneous squamous cell cancer: A case report. Ear Nose Throat J 83: 824, 826-827, 2004.

3. Gupta A, Veness M, De'Ambrosis B, Selva D and Huilgol SC: Management of squamous cell and basal cell carcinomas of the head and neck with perineural invasion. Australas J Dermatol 57: 3-13, 2016.

4. Pour PM, Bell RH and Batra SK: Neural invasion in the staging of pancreatic cancer. Pancreas 26: 322-325, 2003.

5. Feng FY, Qian Y, Stenmark MH, Halverson S, Blas K, Vance S, Sandler HM and Hamstra DA: Perineural invasion predicts increased recurrence, metastasis, and death from prostate cancer following treatment with dose-escalated radiation therapy. Int J Radiat Oncol Biol Phys 81: e361-e367, 2011. 
6. Liebig C, Ayala G, Wilks J, Verstovsek G, Liu H, Agarwal N, Berger DH and Albo D: Perineural invasion is an independent predictor of outcome in colorectal cancer. J Clin Oncol 27: 5131-5137, 2009.

7. Deng J, You Q, Gao Y, Yu Q, Zhao P, Zheng Y, Fang W, Xu N and Teng L: Prognostic value of perineural invasion in gastric cancer: A systematic review and meta-analysis. PLoS One 9: e88907, 2014.

8. Zheng SC, Zhang YR, Luo SY and Zhang LP: The effect of GDNF on matrix-degrading and cell-adhesion during perineural invasion of salivary adenoid cystic carcinoma. Shanghai Kou Qiang Yi Xue 25: 212-216, 2016 (In Chinese).

9. Figueira RC, Gomes LR, Neto JS, Silva FC, Silva ID and Sogayar MC: Correlation between MMPs and their inhibitors in breast cancer tumor tissue specimens and in cell lines with different metastatic potential. BMC Cancer 9: 20, 2009.

10. Batsakis JG: Nerves and neurotropic carcinomas. Ann Otol Rhinol Laryngol 94: 426-427, 1985.

11. Amit M, Na'ara S and Gil Z: Mechanisms of cancer dissemination along nerves. Nat Rev Cancer 16: 399-408, 2016.

12. Abbadie C: Chemokines, chemokine receptors and pain. Trends Immunol 26: 529-534, 2005.

13. Sommer C and Kress M: Recent findings on how proinflammatory cytokines cause pain: Peripheral mechanisms in inflammatory and neuropathic hyperalgesia. Neurosci Lett 361: 184-187, 2004.

14. Charo IF and Ransohoff RM: The many roles of chemokines and chemokine receptors in inflammation. N Engl J Med 354: 610-621, 2006

15. Griffith JW, Sokol CL and Luster AD: Chemokines and chemokine receptors: Positioning cells for host defense and immunity. Annu Rev Immunol 32: 659-702, 2014.

16. Szekanecz Z, Vegvari A, Szabo Z and Koch AE: Chemokines and chemokine receptors in arthritis. Front Biosci (Schol Ed) 2: 153-167, 2010.

17. Gao YJ and Ji RR: Chemokines, neuronal-glial interactions, and central processing of neuropathic pain. Pharmacol Ther 126 56-68, 2010.

18. Rossi D and Zlotnik A: The biology of chemokines and their receptors. Annu Rev Immunol 18: 217-242, 2000.

19. Bonecchi R, Galliera E, Borroni EM, Corsi MM, Locati M and Mantovani A: Chemokines and chemokine receptors: An overview. Front Biosci (Landmark Ed) 14: 540-551, 2009.

20. Bryan SA, Jose PJ, Topping JR, Wilhelm R, Soderberg C, Kertesz D, Barnes PJ, Williams TJ, Hansel TT and Sabroe I: Responses of leukocytes to chemokines in whole blood and their antagonism by novel CC-chemokine receptor 3 antagonists. Am J Respir Crit Care Med 165: 1602-1609, 2002.

21. Old EA and Malcangio M: Chemokine mediated neuron-glia communication and aberrant signalling in neuropathic pain states. Curr Opin Pharmacol 12: 67-73, 2012.

22. Zlotnik A and Yoshie O: The chemokine superfamily revisited. Immunity 36: 705-716, 2012

23. Lefkowitz RJ: Seven transmembrane receptors: A brief personal retrospective. Biochim Biophys Acta 1768: 748-755, 2007.

24. Hamm HE: The many faces of G protein signaling. J Biol Chem 273: 669-672, 1998

25. Violin JD and Lefkowitz RJ: Beta-arrestin-biased ligands at seven-transmembrane receptors. Trends Pharmacol Sci 28 : 416-422, 2007

26. Curnock AP, Logan MK and Ward SG: Chemokine signalling: Pivoting around multiple phosphoinositide 3-kinases. Immunology 105: 125-136, 2002.

27. DeWire SM, Ahn S, Lefkowitz RJ and Shenoy SK: Beta-arrestins and cell signaling. Annu Rev Physiol 69: 483-510, 2007.

28. Logothetis DE, Kurachi Y, Galper J, Neer EJ and Clapham DE: The beta gamma subunits of GTP-binding proteins activate the muscarinic $\mathrm{K}^{+}$channel in heart. Nature 325: 321-326, 1987.

29. Wilson J and Balkwill F: The role of cytokines in the epithelial cancer microenvironment. Semin Cancer Biol 12: 113-120, 2002.

30. Brew R, Erikson JS, West DC, Flanagan BF and Christmas SE: Interleukin-8 as a growth factor for human colorectal carcinoma cells in vitro. Biochem Soc Trans 25: S264, 1997.

31. Di Cesare S, Marshall JC, Logan P, Antecka E, Faingold D, Maloney SC and Burnier MN Jr: Expression and migratory analysis of 5 human uveal melanoma cell lines for CXCL12, CXCL8, CXCL1, and HGF. J Carcinog 6: 2, 2007.

32. Liotta LA: An attractive force in metastasis. Nature 410: 24-25, 2001.
33. Panda S, Padhiary SK and Routray S: Chemokines accentuating protumoral activities in oral cancer microenvironment possess an imperious stratagem for therapeutic resolutions. Oral Oncol 60: 8-17, 2016.

34. Zhang S, Qi L, Li M, Zhang D, Xu S, Wang N and Sun B Chemokine CXCL12 and its receptor CXCR4 expression are associated with perineural invasion of prostate cancer. J Exp Clin Cancer Res 27: 62, 2008.

35. He S, He S, Chen CH, Deborde S, Bakst RL, Chernichenko N, McNamara WF, Lee SY, Barajas F, Yu Z, et al: The chemokine (CCL2-CCR2) signaling axis mediates perineural invasion. Mol Cancer Res 13: 380-390, 2015.

36. Shen Z, Li T, Chen D, Jia S, Yang X, Liang L, Chai J, Cheng X, Yang $X$ and Sun M: The CCL5/CCR5 axis contributes to the perineural invasion of human salivary adenoid cystic carcinoma. Oncol Rep 31: 800-806, 2014.

37. Marchesi F, Piemonti L, Mantovani A and Allavena P: Molecular mechanisms of perineural invasion, a forgotten pathway of dissemination and metastasis. Cytokine Growth Factor Rev 21: 77-82, 2010.

38. Müller A, Homey B, Soto H, Ge N, Catron D, Buchanan ME, McClanahan T, Murphy E, Yuan W, Wagner SN, et al: Involvement of chemokine receptors in breast cancer metastasis. Nature 410: 50-56, 2001

39. Dubový P, Klusáková I, Svízenská I and Brázda V: Spatiotemporal changes of SDF1 and its CXCR4 receptor in the dorsal root ganglia following unilateral sciatic nerve injury as a model of neuropathic pain. Histochem Cell Biol 133: 323-337, 2010

40. Hart CA, Brown M, Bagley S, Sharrard M and Clarke NW: Invasive characteristics of human prostatic epithelial cells: Understanding the metastatic process. Br J Cancer 92: 503-512, 2005.

41. Schimanski CC, Bahre R, Gockel I, Müller A, Frerichs K, Hörner V, Teufel A, Simiantonaki N, Biesterfeld S, Wehler T, et al: Dissemination of hepatocellular carcinoma is mediated via chemokine receptor CXCR4. Br J Cancer 95: 210-217, 2006.

42. Kollmar O, Rupertus K, Scheuer C, Junker B, Tilton B, Schilling MK and Menger MD: Stromal cell-derived factor-1 promotes cell migration and tumor growth of colorectal metastasis. Neoplasia 9: 862-870, 2007.

43. Xu Q, Wang Z, Chen X, Duan W, Lei J, Zong L, Li X, Sheng L, Ma J, Han L, et al: Stromal-derived factor-1 $\alpha /$ CXCL12-CXCR4 chemotactic pathway promotes perineural invasion in pancreatic cancer. Oncotarget 6: 4717-4732, 2015.

44. Kang H, Mansel RE and Jiang WG: Genetic manipulation of stromal cell-derived factor-1 attests the pivotal role of the autocrine SDF-1-CXCR4 pathway in the aggressiveness of breast cancer cells. Int J Oncol 26: 1429-1434, 2005.

45. Matteucci E, Locati M and Desiderio MA: Hepatocyte growth factor enhances CXCR4 expression favoring breast cancer cell invasiveness. Exp Cell Res 310: 176-185, 2005.

46. Vaday GG, Hua SB, Peehl DM, Pauling MH, Lin YH, Zhu L, Lawrence DM, Foda HD and Zucker S: CXCR4 and CXCL12 (SDF-1) in prostate cancer: inhibitory effects of human single chain Fv antibodies. Clin Cancer Res 10: 5630-5639, 2004.

47. Libura J, Drukala J, Majka M, Tomescu O, Navenot JM, Kucia M, Marquez L, Peiper SC, Barr FG, Janowska-Wieczorek A, et al: CXCR4-SDF-1 signaling is active in rhabdomyosarcoma cells and regulates locomotion, chemotaxis, and adhesion. Blood 100: 2597-2606, 2002.

48. Esencay M, Newcomb EW and Zagzag D: HGF upregulates CXCR4 expression in gliomas via NF-kappaB: Implications for glioma cell migration. J Neurooncol 99: 33-40, 2010.

49. Wu M, Chen Q, Li D, Li X, Li X, Huang C, Tang Y, Zhou Y, Wang D, Tang K, et al: LRRC4 inhibits human glioblastoma cells proliferation, invasion, and proMMP-2 activation by reducing SDF-1 alpha/CXCR4-mediated ERK1/2 and Akt signaling pathways. J Cell Biochem 103: 245-255, 2008.

50. Roh J, Muelleman T, Tawfik O and Thomas SM: Perineural growth in head and neck squamous cell carcinoma: A review. Oral Oncol 51: 16-23, 2015.

51. Zhang J, Sarkar S and Yong VW: The chemokine stromal cell derived factor-1 (CXCL12) promotes glioma invasiveness through MT2-matrix metalloproteinase. Carcinogenesis 26: 2069-2077, 2005.

52. Zhu Y, Yang P, Zhang X, Zhang L, Cui G, Wang Q, Lv L, Zhang Y, Xin X, Yan T, et al: The effect and mechanism of CXCR4 silencing on metastasis suppression of human glioma U87 cell line. Anat Rec (Hoboken) 296: 1857-1864, 2013. 
53. Marchesi F, Locatelli M, Solinas G, Erreni M, Allavena P and Mantovani A: Role of CX3CR1/CX3CL1 axis in primary and secondary involvement of the nervous system by cancer. $\mathbf{J}$ Neuroimmunol 224: 39-44, 2010.

54. Bazan JF, Bacon KB, Hardiman G, Wang W, Soo K, Rossi D, Greaves DR, Zlotnik A and Schall TJ: A new class of membranebound chemokine with a CX3C motif. Nature 385: 640-644, 1997

55. Pan Y, Lloyd C, Zhou H, Dolich S, Deeds J, Gonzalo JA, Vath J, Gosselin M, Ma J, Dussault B, et al: Neurotactin, a membraneanchored chemokine upregulated in brain inflammation. Nature 387: 611-617, 1997.

56. Verge GM, Milligan ED, Maier SF, Watkins LR, Naeve GS and Foster AC: Fractalkine (CX3CL1) and fractalkine receptor (CX3CR1) distribution in spinal cord and dorsal root ganglia under basal and neuropathic pain conditions. Eur J Neurosci 20: 1150-1160, 2004.

57. Balkwill FR: Tumour necrosis factor and cancer. Prog Growth Factor Res 4: 121-137, 1992.

58. Zeng Y, Jiang J, Huebener N, Wenkel J, Gaedicke G, Xiang R and Lode HN: Fractalkine gene therapy for neuroblastoma is more effective in combination with targeted IL-2. Cancer Lett 228 187-193, 2005.

59. Locatelli M, Boiocchi L, Ferrero S, Martinelli Boneschi F, Zavanone M, Pesce S, Allavena P, Maria Gaini S, Bello L and Mantovani A: Human glioma tumors express high levels of the chemokine receptor CX3CR1. Eur Cytokine Netw 21: 27-33, 2010.

60. Marchesi F, Piemonti L, Fedele G, Destro A, Roncalli M, Albarello L, Doglioni C, Anselmo A, Doni A, Bianchi P, et al: The chemokine receptor CX3CR1 is involved in the neural tropism and malignant behavior of pancreatic ductal adenocarcinoma. Cancer Res 68: 9060-9069, 2008.

61. Andre F, Cabioglu N, Assi H, Sabourin JC, Delaloge S, Sahin A, Broglio K, Spano JP, Combadiere C, Bucana C, et al: Expression of chemokine receptors predicts the site of metastatic relapse in patients with axillary node positive primary breast cancer. Ann Oncol 17: 945-951, 2006.

62. Shulby SA, Dolloff NG, Stearns ME, Meucci O and Fatatis A: CX3CR1-fractalkine expression regulates cellular mechanisms involved in adhesion, migration, and survival of human prostate cancer cells. Cancer Res 64: 4693-4698, 2004.

63. Muller A, Sonkoly E, Eulert C, Gerber PA, Kubitza R, Schirlau K, Franken-Kunkel P, Poremba C, Snyderman C, Klotz LO, et al: Chemokine receptors in head and neck cancer: Association with metastatic spread and regulation during chemotherapy. Int J Cancer 118: 2147-2157, 2006

64. Fang WB, Jokar I, Zou A, Lambert D, Dendukuri P and Cheng N: CCL2/CCR2 chemokine signaling coordinates survival and motility of breast cancer cells through Smad3 protein- and p42/44 mitogen-activated protein kinase (MAPK)-dependent mechanisms. J Biol Chem 287: 36593-36608, 2012.

65. Dagouassat M, Suffee N, Hlawaty H, Haddad O, Charni F, Laguillier C, Vassy R, Martin L, Schischmanoff PO, Gattegno L, et al: Monocyte chemoattractant protein-1 (MCP-1)/CCL2 secreted by hepatic myofibroblasts promotes migration and invasion of human hepatoma cells. Int J Cancer 126: 1095-1108, 2010.

66. Vaday GG, Peehl DM, Kadam PA and Lawrence DM: Expression of CCL5 (RANTES) and CCR5 in prostate cancer. Prostate 66 : 124-134, 2006

67. Borczuk AC, Papanikolaou N, Toonkel RL, Sole M, Gorenstein LA, Ginsburg ME, Sonett JR, Friedman RA and Powell CA: Lung adenocarcinoma invasion in TGFbetaRIIdeficient cells is mediated by CCL5/RANTES. Oncogene 27: 557-564, 2008

68. Singh S, Singh R, Singh UP, Rai SN, Novakovic KR, Chung LW, Didier PJ, Grizzle WE and Lillard JW Jr: Clinical and biological significance of CXCR5 expressed by prostate cancer specimens and cell lines. Int J Cancer 125: 2288-2295, 2009.

69. Qi XW, Xia SH, Yin Y, Jin LF, Pu Y, Hua D and Wu HR Expression features of CXCR5 and its ligand, CXCL13 associated with poor prognosis of advanced colorectal cancer. Eur Rev Med Pharmacol Sci 18: 1916-1924, 2014.

70. El-Haibi CP, Singh R, Sharma PK, Singh S and Lillard JW Jr: CXCL13 mediates prostate cancer cell proliferation through JNK signalling and invasion through ERK activation. Cell Prolif 44: 311-319, 2011.

71. Zhu Z, Zhang X, Guo H,Fu L, Pan G and Sun Y: CXCL13-CXCR5 axis promotes the growth and invasion of colon cancer cells via PI3K/AKT pathway. Mol Cell Biochem 400: 287-295, 2015.
72. Kim HJ, Kim JS, Kang CD, Lee SJ, Kim JY, Yeon JE, Park JJ, Shim JJ, Byun KS, Bak YT, et al: Expression of epidermal growth factor receptor, ErbB2 and matrix metalloproteinase-9 in hepatolithiasis and cholangiocarcinoma. Korean J Gastroenterol 45: 52-59, 2005 (In Korean).

73. Duan L, Hu XQ, Feng DY, Lei SY and Hu GH: GPC-1 may serve as a predictor of perineural invasion and a prognosticator of survival in pancreatic cancer. Asian J Surg 36: 7-12, 2013

74. Itatsu K, Sasaki M, Yamaguchi J, Ohira S, Ishikawa A, Ikeda H, Sato Y, Harada K, Zen Y, Sato H, et al: Cyclooxygenase-2 is involved in the up-regulation of matrix metalloproteinase-9 in cholangiocarcinoma induced by tumor necrosis factor-alpha. Am J Pathol 174: 829-841, 2009.

75. Yang X, Dai J, Li T, Zhang P, Ma Q, Li Y, Zhou J and Lei D: Expression of EMMPRIN in adenoid cystic carcinoma of salivary glands: Correlation with tumor progression and patients prognosis. Oral Oncol 46: 755-760, 2010.

76. Yang X, Zhang P, Ma Q, Kong L, Li Y, Liu B and Lei D: EMMPRIN contributes to the in vitro invasion of human salivary adenoid cystic carcinoma cells. Oncol Rep 27: 1123-1127, 2012

77. Yang X, Zhang P, Ma Q, Kong L, Li Y, Liu B and Lei D: EMMPRIN silencing inhibits proliferation and perineural invasion of human salivary adenoid cystic carcinoma cells in vitro and in vivo. Cancer Biol Ther 13: 85-91, 2012.

78. Anton ES, Weskamp G, Reichardt LF and Matthew WD: Nerve growth factor and its low-affinity receptor promote Schwann cell migration. Proc Natl Acad Sci USA 91: 2795-2799, 1994.

79. Zhu Z, Kleeff J, Kayed H, Wang L, Korc M, Büchler MW and Friess $\mathrm{H}$ : Nerve growth factor and enhancement of proliferation, invasion, and tumorigenicity of pancreatic cancer cells. Mol Carcinog 35: 138-147, 2002.

80. Zhu Z, Friess H, diMola FF, Zimmermann A, Graber HU, Korc M and Büchler MW: Nerve growth factor expression correlates with perineural invasion and pain in human pancreatic cancer. J Clin Oncol 17: 2419-2428, 1999.

81. DeSchryver-Kecskemeti K, Balogh K and Neet KE: Nerve growth factor and the concept of neural-epithelial interactions. Immunohistochemical observations in two cases of vasitis nodosa and six cases of prostatic adenocarcinoma. Arch Pathol Lab Med 111: 833-835, 1987.

82. Okada Y, Eibl G, Duffy JP, Reber HA and Hines OJ: Glia cell-derived neurotrophic factor upregulates the expression and activation of matrix metalloproteinase- 9 in human pancreatic cancer. Surgery 134: 293-299, 2003.

83. Okada Y, Eibl G, Guha S, Duffy JP, Reber HA and Hines OJ: Nerve growth factor stimulates MMP-2 expression and activity and increases invasion by human pancreatic cancer cells. Clin Exp Metastasis 21: 285-292, 2004.

84. Moscatelli I, Pierantozzi E, Camaioni A, Siracusa G and Campagnolo L: p75 neurotrophin receptor is involved in proliferation of undifferentiated mouse embryonic stem cells. Exp Cell Res 315: 3220-3232, 2009.

85. Wang L, Sun M, Jiang Y, Yang L, Lei D, Lu C, Zhao Y, Zhang P, Yang Y and Li J: Nerve growth factor and tyrosine kinase A in human salivary adenoid cystic carcinoma: expression patterns and effects on in vitro invasive behavior. J Oral Maxillofac Surg 64: 636-641, 2006.

86. Taylor S, Herrington S, Prime W, Rudland PS and Barraclough R: S100A4 (p9Ka) protein in colon carcinoma and liver metastases: Association with carcinoma cells and T-lymphocytes. Br J Cancer 86: 409-416, 2002.

87. Jiang WG: E-cadherin and its associated protein catenins, cancer invasion and metastasis. Br J Surg 83: 437-446, 1996.

88. Schmidt KN, Amstad P, Cerutti P and Baeuerle PA: Identification of hydrogen peroxide as the relevant messenger in the activation pathway of transcription factor NF-kappaB. Adv Exp Med Biol 387: 63-68, 1996

89. Wang CY, Mayo MW and Baldwin AS Jr: TNF- and cancer therapy-induced apoptosis: Potentiation by inhibition of NF-kappaB. Science 274: 784-787, 1996.

90. Huang S, Pettaway CA, Uehara H, Bucana CD and Fidler IJ: Blockade of NF-kappaB activity in human prostate cancer cells is associated with suppression of angiogenesis, invasion, and metastasis. Oncogene 20: 4188-4197, 2001.

91. Huang S, DeGuzman A, Bucana CD and Fidler IJ: Nuclear factor-kappaB activity correlates with growth, angiogenesis, and metastasis of human melanoma cells in nude mice. Clin Cancer Res 6: 2573-2581, 2000 
92. Sun X, Cheng G, Hao M, Zheng J, Zhou X, Zhang J, Taichman RS, Pienta KJ and Wang J: CXCL12 / CXCR4 / CXCR7 chemokine axis and cancer progression. Cancer Metastasis Rev 29: 709-722, 2010.

93.Zheng Y, Miu Y, Yang X, Yang X and Zhu M: CCR7 Mediates TGF- $\beta 1$-induced human malignant glioma invasion, migration, and epithelial-mesenchymal transition by activating MMP $2 / 9$ through the nuclear factor kappaB signaling pathway. DNA Cell Biol 36: 853-861, 2017.

94.Zhong W, Tong Y, Li Y, Yuan J, Hu S, Hu T and Song G: Mesenchymal stem cells in inflammatory microenvironment potently promote metastatic growth of cholangiocarcinoma via activating $\mathrm{Akt} / \mathrm{NF}-\mathrm{\kappa B}$ signaling by paracrine CCL5. Oncotarget 8: 73693-73704, 2017.

95. Wang H, Cai J, Du S, Guo Z, Xin B, Wang J, Wei W and Shen X: Fractalkine/CX3CR1 induces apoptosis resistance and proliferation through the activation of the $\mathrm{AKT} / \mathrm{NF}-\kappa \mathrm{B}$ cascade in pancreatic cancer cells. Cell Biochem Funct 35: 315-326, 2017.

96. Anwar TE and Kleer CG: Tissue-based identification of stem cells and epithelial-to-mesenchymal transition in breast cancer. Hum Pathol 44: 1457-1464, 2013.

97. Olmeda D, Montes A, Moreno-Bueno G, Flores JM, Portillo F and Cano A: Snai1 and Snai2 collaborate on tumor growth and metastasis properties of mouse skin carcinoma cell lines. Oncogene 27: 4690-4701, 2008

98. Carpenter RL, Paw I, Dewhirst MW and Lo HW: Akt phosphorylates and activates HSF-1 independent of heat shock, leading to Slug overexpression and epithelial-mesenchymal transition (EMT) of HER2-overexpressing breast cancer cells. Oncogene 34: 546-557, 2015.

99. Hotz B, Arndt M, Dullat S, Bhargava S, Buhr HJ and Hotz HG: Epithelial to mesenchymal transition: Expression of the regulators snail, slug, and twist in pancreatic cancer. Clin Cancer Res 13: 4769-4776, 2007.

100. Kalluri R and Weinberg RA: The basics of epithelial-mesenchymal transition. J Clin Invest 119: 1420-1428, 2009.

101. Thiery JP, Acloque H, Huang RY and Nieto MA: Epithelialmesenchymal transitions in development and disease. Cell 139: 871-890, 2009.

102. He Q, Zhou X, Li S, Jin Y, Chen Z, Chen D, Cai Y, Liu Z, Zhao T and Wang A: MicroRNA-181a suppresses salivary adenoid cystic carcinoma metastasis by targeting MAPK-Snai2 pathway. Biochim Biophys Acta 1830: 5258-5266, 2013.

103. Chang B, Yang H, Jiao Y, Wang K, Liu Z, Wu P, Li S and Wang A: SOD2 deregulation enhances migration, invasion and has poor prognosis in salivary adenoid cystic carcinoma. Sci Rep 6: 25918, 2016.

104. Wang H, Liang X, Li M, Tao X, Tai S, Fan Z, Wang Z, Cheng B and Xia J: Chemokine (CC motif) ligand 18 upregulates Slug expression to promote stem-cell like features by activating the mammalian target of rapamycin pathway in oral squamous cell carcinoma. Cancer Sci 108: 1584-1593, 2017.

105.Zhong G, Chen L, Yin R, Qu Y, Bao Y, Xiao Q, Zhang Z, Shen Y, Li C, Xu Y, et al: Chemokine (C-C motif) ligand 21/C-C chemokine receptor type 7 triggers migration and invasion of human lung cancer cells by epithelial-mesenchymal transition via the extracellular signal-regulated kinase signaling pathway. Mol Med Rep 15: 4100-4108, 2017.

106.Li G, Yang Y, Xu S, Ma L, He M and Zhang Z: Slug signaling is up-regulated by CCL21/CCR7 [corrected] to induce EMT in human chondrosarcoma. Med Oncol 32: 478, 2015

107. Hou X, Zhang Y and Qiao H: CCL18 promotes the invasion and migration of gastric cancer cells via ERK1/2/NF- $\mathrm{BB}$ signaling pathway. Tumour Biol 37: 641-651, 2016.

108.Zhao S, Wang J and Qin C: Blockade of CXCL12/CXCR4 signaling inhibits intrahepatic cholangiocarcinoma progression and metastasis via inactivation of canonical Wnt pathway. J Exp Clin Cancer Res 33: 103, 2014.

109. Murre C, McCaw PS, Vaessin H, Caudy M, Jan LY, Jan YN, Cabrera CV, Buskin JN, Hauschka SD, Lassar AB, et al: Interactions between heterologous helix-loop-helix proteins generate complexes that bind specifically to a common DNA sequence. Cell 58: 537-544, 1989.

110. Ip YT, Park RE, Kosman D, Yazdanbakhsh K and Levine M: dorsal-twist interactions establish snail expression in the presumptive mesoderm of the Drosophila embryo. Genes Dev 6: 1518-1530, 1992

111. Yang J, Mani SA, Donaher JL, Ramaswamy S, Itzykson RA, Come C, Savagner P, Gitelman I, Richardson A and Weinberg RA: Twist, a master regulator of morphogenesis, plays an essential role in tumor metastasis. Cell 117: 927-939, 2004.
112. Kwok WK, Ling MT, Lee TW, Lau TC, Zhou C, Zhang X, Chua CW, Chan KW, Chan FL, Glackin C, et al: Up-regulation of TWIST in prostate cancer and its implication as a therapeutic target. Cancer Res 65: 5153-5162, 2005.

113. Rosivatz E, Becker I, Specht K, Fricke E, Luber B, Busch R, Höfler H and Becker KF: Differential expression of the epithelial-mesenchymal transition regulators snail, SIP1, and twist in gastric cancer. Am J Pathol 161: 1881-1891, 2002

114. Wang D, Rai B, Qi F, Liu T, Wang J, Wang X and Ma B: Influence of the Twist gene on the invasion and metastasis of colon cancer. Oncol Rep 39: 31-44, 2018

115. Chen W, Gao Q, Han S, Pan F and Fan W: The CCL2/CCR2 axis enhances IL-6-induced epithelial-mesenchymal transition by cooperatively activating STAT3-Twist signaling. Tumour Biol 36: 973-981, 2015.

116. Low-Marchelli JM, Ardi VC, Vizcarra EA, van Rooijen N, Quigley JP and Yang J: Twist1 induces CCL2 and recruits macrophages to promote angiogenesis. Cancer Res 73: 662-671, 2013.

117. Xu C, Liu Y, Xiao L, Guo C, Deng S, Zheng S and Zeng E: The involvement of anterior gradient 2 in the stromal cell-derived factor 1-induced epithelial-mesenchymal transition of glioblastoma. Tumour Biol 37: 6091-6097, 2016.

118. Koo YJ, Kim TJ, Min KJ, So KA, Jung US and Hong JH: CXCL11 mediates TWIST1-induced angiogenesis in epithelial ovarian cancer. Tumour Biol 39: 1010428317706226, 2017.

119. Li K, Xu B, Xu G and Liu R: CCR7 regulates Twist to induce the epithelial-mesenchymal transition in pancreatic ductal adenocarcinoma. Tumour Biol 37: 419-424, 2016.

120. Franciszkiewicz K, Boissonnas A, Boutet $\mathrm{M}$, Combadière $\mathrm{C}$ and Mami-Chouaib F: Role of chemokines and chemokine receptors in shaping the effector phase of the antitumor immune response. Cancer Res 72: 6325-6332, 2012.

121. Wang D, Dubois RN and Richmond A: The role of chemokines in intestinal inflammation and cancer. Curr Opin Pharmacol 9: 688-696, 2009.

122. Celesti G, Di Caro G, Bianchi P, Grizzi F, Marchesi F, Basso G, Rahal D, Delconte G, Catalano M, Cappello P, et al: Early expression of the fractalkine receptor CX3CR1 in pancreatic carcinogenesis. Br J Cancer 109: 2424-2433, 2013.

123. Schioppa T, Uranchimeg B, Saccani A, Biswas SK, Doni A, Rapisarda A, Bernasconi S, Saccani S, Nebuloni M, Vago L, et al: Regulation of the chemokine receptor CXCR4 by hypoxia. J Exp Med 198: 1391-1402, 2003.

124. Ceradini DJ, Kulkarni AR, Callaghan MJ, Tepper OM, Bastidas N, Kleinman ME, Capla JM, Galiano RD, Levine JP and Gurtner GC: Progenitor cell trafficking is regulated by hypoxic gradients through HIF-1 induction of SDF-1. Nat Med 10: 858-864, 2004.

125. Rong Y,Durden DL, Van MeirEG and BratDJ:'Pseudopalisading' necrosis in glioblastoma: A familiar morphologic feature that links vascular pathology, hypoxia, and angiogenesis. J Neuropathol Exp Neurol 65: 529-539, 2006.

126. Lin S, Wan S, Sun L, Hu J, Fang D, Zhao R, Yuan S and Zhang L: Chemokine C-C motif receptor 5 and $\mathrm{C}-\mathrm{C}$ motif ligand 5 promote cancer cell migration under hypoxia. Cancer Sci 103: 904-912, 2012

127.Li Y, Qiu X, Zhang S, Zhang Q and Wang E: Hypoxia induced CCR7 expression via HIF-1alpha and HIF-2alpha correlates with migration and invasion in lung cancer cells. Cancer Biol Ther 8: 322-330, 2009.

128. Zhao T, Gao S, Wang X, Liu J, Duan Y, Yuan Z, Sheng J, Li S, Wang F, Yu M, et al: Hypoxia-inducible factor- $1 \alpha$ regulates chemotactic migration of pancreatic ductal adenocarcinoma cells through directly transactivating the CX3CR1 gene. PLoS One 7: e43399, 2012.

129. Xiao LJ, Chen YY, Lin P, Zou HF, Lin F, Zhao LN, Li D, Guo L, Tang JB, Zheng XL, et al: Hypoxia increases CX3CR1 expression via HIF-1 and NF- $\kappa \mathrm{B}$ in androgen-independent prostate cancer cells. Int J Oncol 41: 1827-1836, 2012.

130. Trusolino L, Cavassa S, Angelini P, Andó M, Bertotti A, Comoglio PM and Boccaccio C: HGF/scatter factor selectively promotes cell invasion by increasing integrin avidity. FASEB J 14: $1629-1640,2000$

131. Matteucci E, Modora S, Simone M and Desiderio MA: Hepatocyte growth factor induces apoptosis through the extrinsic pathway in hepatoma cells: Favouring role of hypoxiainducible factor-1 deficiency. Oncogene 22: 4062-4073, 2003. 
132.Zhang YW, Su Y, Volpert OV and Vande Woude GF: Hepatocyte growth factor/scatter factor mediates angiogenesis through positive VEGF and negative thrombospondin 1 regulation. Proc Natl Acad Sci USA 100: 12718-12723, 2003.

133. Tacchini L, De Ponti C, Matteucci E, Follis R and Desiderio MA: Hepatocyte growth factor-activated NF-kappaB regulates HIF-1 activity and ODC expression, implicated in survival, differently in different carcinoma cell lines. Carcinogenesis 25: 2089-2100, 2004.
134. Semenza GL: Targeting HIF-1 for cancer therapy. Nat Rev Cancer 3: 721-732, 2003.

135. Niu G and Chen X: Vascular endothelial growth factor as an anti-angiogenic target for cancer therapy. Curr Drug Targets 11: 1000-1017, 2010.

136. Owusu BY, Galemmo R, Janetka J and Klampfer L: Hepatocyte growth factor, a key tumor-promoting factor in the tumor microenvironment. Cancers (Basel) 9: 9, 2017. 